\title{
The orthodenticle gene encodes a novel homeo domain protein involved in the development of the Drosophila nervous system and ocellar visual structures
}

\author{
Robert Finkelstein, ${ }^{1}$ David Smouse, ${ }^{1}$ Theresa M. Capaci, ${ }^{1}$ Allan C. Spradling, ${ }^{2}$ and Norbert Perrimon ${ }^{1}$ \\ ${ }^{1}$ Department of Genetics, Howard Hughes Medical Institute, Harvard Medical School, Boston, Massachusetts 02115 USA; \\ ${ }^{2}$ Department of Embryology, Howard Hughes Medical Institute, Carnegie Institution of Washington, Baltimore, Maryland \\ 21210 USA
}

The orthodenticle (otd) locus of Drosophila is required for embryonic development, and null mutations of otd cause defects in head development and segmental patterning. We show here that otd is necessary for the formation of the embryonic central nervous system (CNS). otd mutations result in the formation of an abnormal neuropil and in the disappearance of identified neurons associated with the midline of the CNS. In addition, otd is allelic to ocelliless (oc), a mutation that causes the deletion of the ocelli of the adult fly. We have identified a transcription unit corresponding to the otd locus and find that it is expressed early in a stripe near the anterior pole of the cellular blastoderm and later in the region of the CNS from which these neurons normally arise. The predicted otd protein contains a well-conserved homeo domain and is therefore likely to be a transcriptional regulator involved in specifying cell fate both in the embryonic CNS and in the ocelli.

[Key Words: Homeo domain; Drosophila; central nervous system; ocelli]

Received April 20, 1990; revised version accepted July 12, 1990.

The development of the Drosophila nervous system is a highly stereotyped process involving the specification of a complex pattern of neuronal and non-neuronal cells. One of the first steps in this process occurs early in embryonic development when neuronal precursors sort out from epidermal precursors within the neurogenic region (Campos-Ortega and Hartenstein 1985). A number of loci have been identified that are required in the decision between neuronal and epidermal fates (for review, see Campos-Ortega 1988). Mutations at these loci cause the overproduction of neuroblasts at the expense of epidermal progenitors (Lehmann et al. 1981, 1983). Genetic and molecular studies have provided models for a pathway involved in this step of neuronal development (Campos-Ortega 1988). In addition to this process, individual neuronal precursors and their progeny must acquire specific cellular identities. Elegant studies in Drosophila and grasshopper embryos have described the development of specific neurons during the formation of the CNS (Hartenstein and Campos-Ortega 1984; Doe and Goodman 1985a,b; Kuwada and Goodman 1985).

The molecular mechanisms underlying the specification of cell fate within the CNS remain largely obscure. To investigate how the pattern of specific neurons is generated, it will be necessary to first identify loci that affect identified cells in the CNS and to then characterize their gene products. Two such loci are single- minded (Crews et al. 1988; Thomas et al. 1988) and slit (Rothberg et al. 1988). Mutations in these genes result in the absence or abnormal development of identified neuronal and non-neuronal precursors along the midline of the ventral nerve cord. Both mutations result in the collapse of the CNS axon scaffold along its longitudinal axis. The sequence of the slit gene product, which contains epidermal growth factor-like repeats, suggests a function for cell-cell interaction in this process of pattern formation. In addition, a number of loci that are required for segmentation have been shown to also affect subsets of neurons in the developing CNS (Doe et al. 1987, 1988; Patel et al. 1989a).

We are interested in identifying new loci required for specifying the fates of particular neuronal precursors and their progeny. To this end, we have screened $\sim 500$ previously identified lethal mutations for subtle and specific CNS phenotypes (D. Smouse and N. Perrimon, unpubl.). Here, we describe the molecular and phenotypic characterization of one such locus, orthodenticle (otd). Mutations at otd, located on the X-chromosome, were originally isolated in a large-scale screen for loci that affect development of the larval cuticle (Wieschaus et al. 1984). In this study it was demonstrated that otd embryos have defects in denticle belt formation, as well as in head development. We show here that in otd embryos, embryonic CNS development is defective, partic- 
ularly in the formation of the horizontal commissures in each segment. In addition, we have identified a particular subset of neurons whose development is perturbed by mutations in this gene. We also show that otd is allelic to ocelliless (oc), a mutation that causes the complete deletion of the ocelli of the adult fly. We have characterized the otd gene at the molecular level and analyzed its pattern of expression in the developing embryo. Finally, we present the sequence of the otd gene and show that it encodes a protein containing a homeo domain.

\section{Results}

\section{Development of the CNS in otd embryos}

The CNS of a 14-hr Drosophila embryo consists of a segmented ventral nerve cord with $\sim 500$ neurons per segment (Goodman et al. 1984). The axons of the ventral nerve cord form a ladder-like neuropil composed of a pair of horizontal commissures per segment (anterior and posterior) and a pair of longitudinal axon bundles connecting the segments (longitudinal connectives). The pattern of cell bodies and axon fascicles in the embryo is made apparent by staining with an anti-horseradish peroxidase (anti-HRP) antibody, which labels all neuronal cell membranes in insect embryos (Jan and Jan 1982). Figure 1, A and D, shows the ladder-like structure of the ventral nerve cords of 14 -hr wild-type embryos stained with anti-HRP. A distinct space separates the anterior and posterior commissures, whereas a larger gap separates the posterior commissure from the next neuromere. The longitudinal connectives are also well-separated and, like the commissures, very regular in appearance and uniform from segment to segment. In embryos lacking otd function (Fig. 1B and E), the neuropil of the ventral nerve cord forms abnormally. In particular, the commissures within each segment appear to be fused. The gap separating each fused commissure from that of the next segment is still present. The gap separating the posterior commissure from the anterior commissure of the next segment is still present. The longitudinal connectives form in otd mutants, although the space separating them is often narrower than in wild-type embryos. The otd mutant phenotype is distinct from that caused by single-minded or slit mutations, which induce a more severe fusion of the embryonic CNS (Fig. $1 \mathrm{C})$.

To characterize further the defects in CNS development in otd embryos, the phenotype was analyzed at the cellular level. The midline of the wild-type CNS is occupied by a specific subset of neuronal and non-neuronal cells that have recently been investigated (Crews et al. 1988; Rothberg et al. 1988; Thomas et al. 1988; Jacobs and Goodman 1989a,b). Many of these midline cells are derived from the specialized mesectoderm cells that delaminate from the ventral surface of the embryo slightly before the first wave of true neuroblasts delaminate. The mesectoderm cells produce a set of neural precursors,

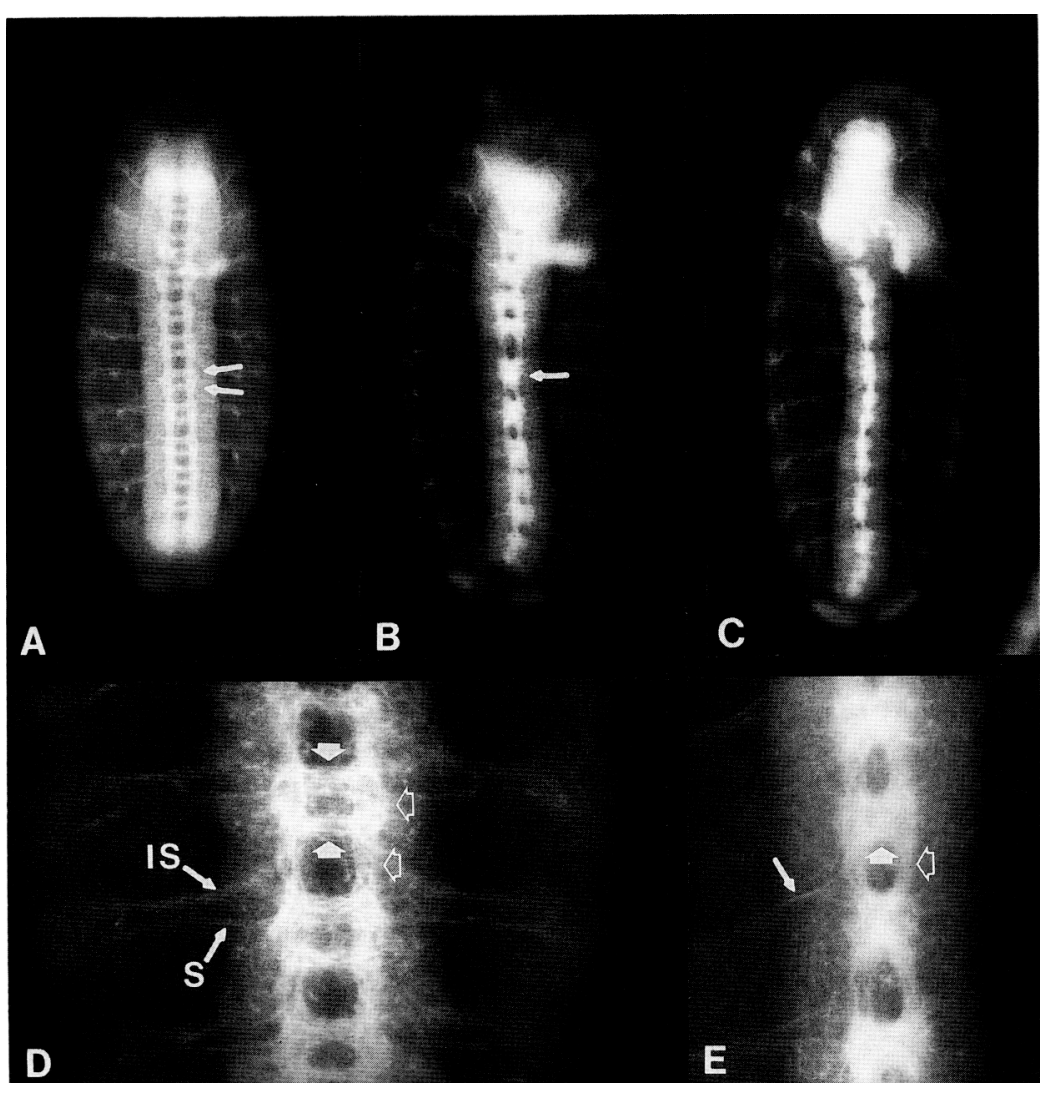

Figure 1. Axon phenotype in otd mutant embryos. All embryos are stained with anti-HRP antisera and are oriented to show the ventral nerve cords; anterior is up. (A) Wild-type embryo showing the axon ladder composed of two horizontal commissures per segment (arrows) and two longitudinal connectives; $(B)$ otd mutant embryo showing the aberrant commissure formation in each segment (arrow); $(C)$ An embryo homozygous for the slit mutation, which results in defective development of cells derived from the mesectoderm (Rothberg et al. 1988). The phenotype is distinct from that of otd mutants; note that the fusion in slit embryos is more severe and occurs along the entire length of the nerve cord, whereas the defect in otd embryos is predominantly in the region of the commissures. (D) Higher magnification of a wild-type nerve cord. The commissures (solid arrowheads), particularly the space separating them (open arrowheads), are quite evident. The segmental (S) and intersegmental (IS) nerves, which lead to the periphery, are indicated (solid arrows). (E) Higher magnification of an otd nerve cord. The defect in commissure formation (solid arrowhead) can be seen; however, the commissures in adjacent segments are well separated. The longitudinal connectives (open arrowhead) are separated as well, in contrast to the connectives in the slit mutant embryo. The segmental and intersegmental nerves appear normal in the otd embryo /solid arrow). 
including the median neuroblast (MNB), the midline precursors (MPs), and a population of midline glial cells (Jacobs and Goodman 1989a). Each MP divides once to produce two neuronal progeny. The ventral unpaired median neurons, or VUMs, are thought to be the progeny of MPs 4-6 (Jacobs and Goodman 1989b). We have used a lacZ insertion line (see Materials and methods), in which $\beta$-galactosidase is expressed in the VUMs and several other neurons not associated with the ventral midline (D. Smouse, unpubl.) to follow the development of the VUMs in wild-type and otd embryos (Fig. 2). The VUMs initially occupy a dorsal position in the wild-type ventral nerve cord at $12 \mathrm{hr}$ but ultimately migrate more ventrally by $14 \mathrm{hr}$ (Fig. 2). In otd mutant embryos, the VUMs appear at their normal positions at $12 \mathrm{hr}$ but do not appear to migrate ventrally and are absent in most segments by $14 \mathrm{hr}$. The most likely interpretation of these data is that the VUMs undergo their initial development normally in otd mutants but die between 12 and $14 \mathrm{hr}$. Preliminary evidence suggests that a subset of the midline glia may be similarly affected in otd mutants (E. Noll, unpubl.). Mutations in otd also appear to affect the development of other midline-associated neurons in addition to the VUMs. A monoclonal antibody (Patel et al. 1989b) that recognizes the engrailed (en) and invected proteins stains at least two sets of medial neurons in each segment. These include the progeny of the MNB (Patel et al. 1989a) and a group of three to four large ventral neurons of unknown origin (N.H. Patel, pers. comm.; D. Smouse, unpubl.). Both groups of $\mathrm{en}^{+}$neurons are missing in otd embryos (Fig. 3 . The neurons that are labeled by the en antibody, the $l a c Z$ insertion line, or an even-skipped antibody (antieve; Doe et al. 1988) but that are not associated with the midline do not appear to be affected by the mutation (Figs. 2 and 3). This indicates that cell death (or abnormal development) in the CNS of otd embryos is not a general phenomenon but is instead restricted to a specific subset of cells.

otd is allelic to ocelliless

otd has been localized cytologically to the 7F1-8A5 region of the X-chromosome (Wieschaus et al. 1984). The seven existing otd alleles, including the $\mathrm{X}$-ray-induced deficiency ot $d^{I A 101}$, are all recessive-lethal and behave as null mutations (see Materials and methods). The cytological interval containing otd has also been shown to contain the ocelliless (oc) locus (Bedichek 1934). Flies homozygous or hemizygous for $O c$ are viable but lack the ocelli, which are photoreceptor organs located between the compound eyes on the vertex of the adult head. In addition, specific bristles (e.g., the postvertical and ocellar bristles) in the region of the ocelli are usually deleted or abnormal. Although flies heterozygous for a wild-type X-chromosome and null alleles of otd are viable, they exhibit a dominant phenotype of altered bristle patterns in the region of the ocelli. This phenotype resembles that of flies homozygous for a weak allele of $o c\left(o c^{d b}\right.$; data not shown). Because of this pheno- type and the proximity of these two loci, their genetic relationship was investigated. Flies that are transheterozygous for $O C$ alleles and null alleles of otd are phenotypically oc (Fig. 4). These results suggest that the adult $o c$ and embryonic lethal phenotypes are associated with lesions in the same locus.

\section{Molecular structure of the otd locus}

To identify the DNA region encoding the otd gene product, we utilized a series of overlapping bacteriophage clones isolated as part of an analysis of chorion gene amplification (Spradling and Mahowald 1981). The clones used in this study (Fig. 5) represent a subset of the bacteriophage walk and include $\sim 80 \mathrm{~kb}$ of genomic DNA. To localize the otd gene, we mapped by Southern analysis the DNA lesions associated with several of the alleles described above. As shown in Figure 5, these alleles show alterations in a relatively small region of genomic DNA. In particular, the ot d/A101 mutation represents a small deletion within this region.

To locate transcription units in this region, we performed Northern analysis by using ${ }^{32} \mathrm{P}$-labeled bacteriophage clones from the walk, as well as various subclones derived from these phage. When the 4.0-kb EcoRI fragment from $\lambda$ oc100 (Fig. 5) is used as a probe on developmental Northern blots, an mRNA of $\sim 4.7 \mathrm{~kb}$ is detected (Fig. 6). This transcript is detected by DNA lying just distal to the oc breakpoints $[\operatorname{In}(1) \Delta 49, \quad O c$ and $\left.T(1 ; 2) o c^{\gamma a 1}\right]$ and is contained largely within the otd deletion $\left(o t d^{A 101}\right)$. Because it is the only detectable embryonic mRNA in the vicinity of these DNA lesions, and because its expression pattern (Fig. 7) correlates well with the mutant phenotype, it will subsequently be referred to as the otd transcript. Transcription is detectable from early embryonic stages through late pupation, with the highest levels occurring between 4 and $13 \mathrm{hr}$ of embryogenesis. During this time period, the critical stages of neurogenesis occur, including the emergence of neuroblasts and the subsequent extension of pioneer growth cones to form the axonal scaffold. Some variation in the size of the mRNA derived from this region appears to occur, particularly during the first several hours of embryonic development, when a slightly smaller transcript is detected. This maternally derived mRNA may represent an alternatively processed transcript from this locus.

\section{Isolation and sequence analysis of an otd CDNA clone}

To localize the position of the otd transcript and to obtain sequence information about its predicted protein product, we isolated cDNAs from a 9- to 12-hr embryonic cDNA library obtained from $\mathrm{K}$. Zinn and $\mathrm{C}$. Goodman. The probe used was the 4.0-kb EcoRI fragment employed above for Northern analysis. The longest cDNA obtained is $\sim 3.8 \mathrm{~kb}$ in size and hybridizes to the EcoRI fragments indicated in Figure 5. It should be noted that this longest clone is $\sim 900$ bp shorter than the mRNA detected during embryogenesis by Northern 
analysis. The sequence of this cDNA is shown in Figure 8. Analysis of possible reading frames reveals only one open reading frame (ORF) of significant length. This frame extends from nucleotide 645 to 2793 . The first methionine of this ORF begins at nucleotide position 780. This methionine is not in a particularly favorable context for translational initiation (Kozak 1984; Cavener 1987), and we have no evidence that it is the
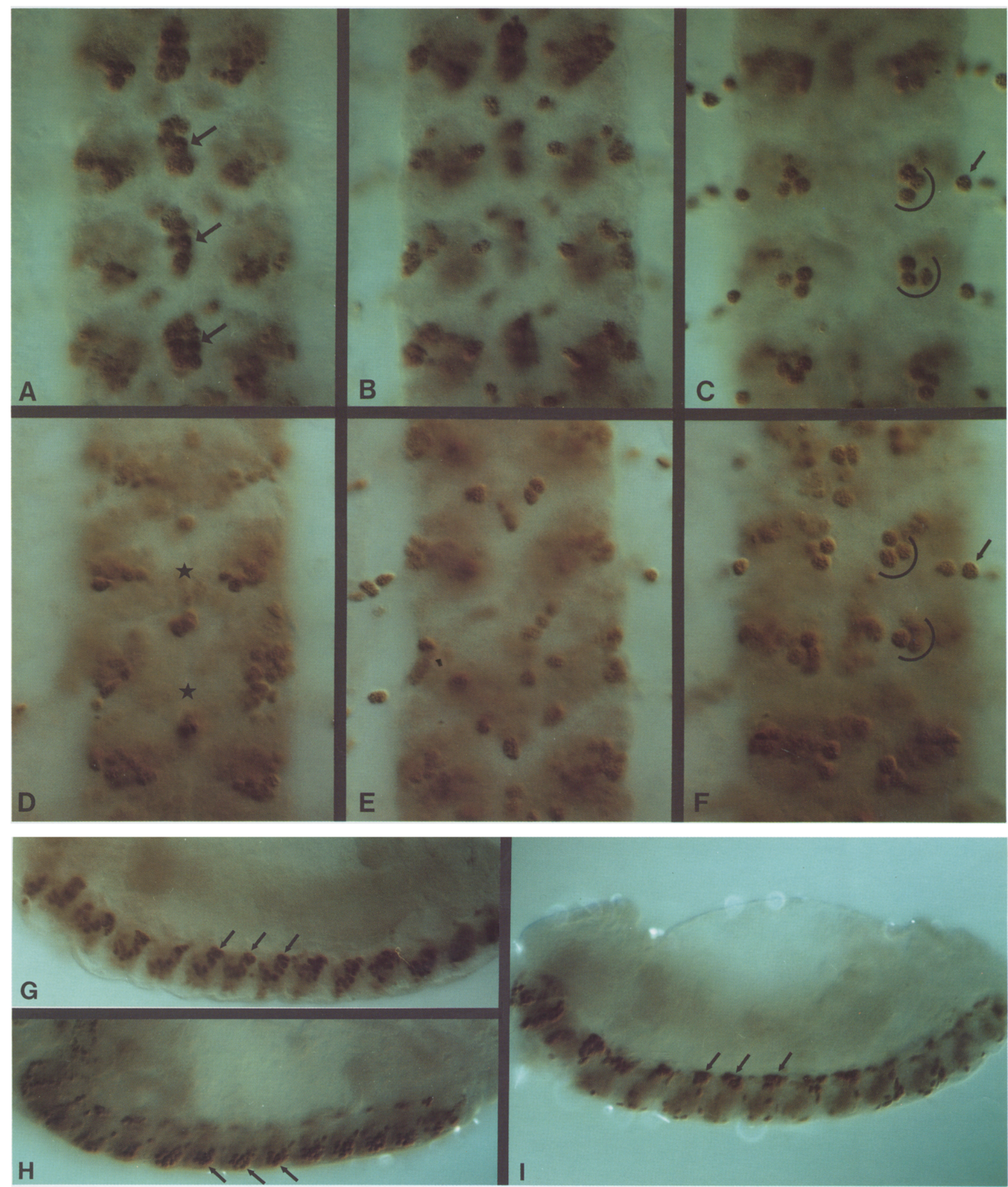

Figure 2. (See following page for legend.) 
amino-terminal residue of the protein. At the 3' end, no polyadenylation signal (Proudfoot and Brownlee 1976) or poly(A) tract is present, so it is likely that the cDNA is the result of internal priming within the 3 '-untranslated region of the mRNA. Partial sequence analysis of four other cDNA clones showed that their ends either approximately coincide with, or lie within, this $3.8-\mathrm{kb}$ cDNA.

To determine whether there is any resemblance between the predicted otd gene product and other known proteins, the amino acid sequence was compared to the sequences in the NBRF, Genbank, and Doolittle data bases. Aside from limited similarities based on repetitive regions of the otd protein (e.g., homopolymeric tracts of glycine and histidine), no significant overall resemblance was found to any known protein. To continue this analysis, the predicted protein was analyzed for potential sequence motifs that might provide information about its function. In this analysis, only one significant similarity, a homeo domain, was found and will be described below.

The predicted otd protein contains multiple repeats consisting of single amino acids (e.g., glycine, serine, and glutamine) and pairs of amino acids (e.g., alternating glycine and valine residues). A number of these repeats are the result of the high content of CAG/A sequences in various regions of the coding sequence. The presence of this nucleotide sequence motif has been noted in a number of other developmentally important Drosophila proteins, including Notch (Wharton et al. 1985a,b), single-minded (Crews et al. 1988), and en (Poole et al. 1985|. In addition to these repeats, the predicted otd protein contains a stretch of 19 amino acids (beginning at nucleotide 1464) that is precisely repeated in tandem. The functional role of these different types of repeated sequences is unclear. One possibility is that some of the repeats have been generated by polymerase errors during DNA replication relatively recently (Dover 1989) and have little functional significance. For example, in the case of the 19-amino-acid tandem repeat, the sequences of the two reiterated units are also virtually identical at the nucleotide level. The absence of third base differences between these two segments provides no evidence for any functional conservation at the protein level. However, in other regions of the protein (e.g., the repeated glycine-valine motif that begins at nucleotide 1887), a number of third base differences among the triplets encoding these two amino acids does exist. This suggests that this amino acid motif may have been conserved for functional reasons. Finally, as shown in Figure 8 , the predicted otd protein contains several candidate PEST sequences (Rogers et al. 1986). This sequence motif has been hypothesized to act as a tag for rapid protein degradation. Structure-function analysis, as well as sequence comparisons among different Drosophila species, should provide more information about how these various repetitive elements are generated and about their possible functions in the otd protein.

\section{The predicted otd protein contains a homeo domain}

As mentioned above, sequence analysis of the otd protein reveals the presence of a homeo domain. Homeo domains, which consist of $\sim 60$ amino acids (for review, see Scott et al. 1989), contain a number of highly conserved amino acids that are presumably important to their function. As shown in Figure 9, the four invariant residues (positions 49, 50,52, and 54) that lie in the carboxy-terminal region of the putative "recognition" helix are all conserved in the otd homeo domain. Eight other highly conserved amino acid positions $(6,13,17,21,41$, 46,56 , and 58) match the consensus defined by Scott and colleagues. Homeo domains can also be divided into a number of classes based on overall amino acid sequence (McGinnis et al. 1984; Scott et al. 1989). By this criterion, the otd homeo domain is most related to the paired (prd) group, which includes prd, gsbBSH4, and gsbBSH9. For example, the otd domain shares 37 identical amino acids with the prd homeo domain. However, it is significantly less similar to the three members of the prd class than the members are to each other (e.g., prd and gsbBSH4 share 50 identical amino acids), suggesting that the otd homeo domain does not really fall into any of the existing classes. Finally, recent studies (Hanes and Brent 1989; Treisman et al. 1989) suggest a highly important role for amino acid 51 of the homeo domain, which lies within the putative recognition helix (helix 3 in Fig. 9|, in determining the binding specificity of homeo domain-containing proteins to DNA. It should be noted that the otd homeo domain, which has a lysine in this position, is identical only to that of bicoid. This suggests a similar binding specificity for these two proteins.

Figure 2. Phenotype of the VUMs in otd mutant embryos. $(A-C)$ Ventral $(A)$ to dorsal focal planes through the ventral nerve cord of a wild-type embryo at $13 \mathrm{hr}$. The embryo carries a lacZ insertion at $45 \mathrm{C}$ that expresses $\beta$-galactosidase in a subset of neuronal nuclei. In the ventral plane of focus $(A)$, the VUMs are the prominent cells along the ventral midline, which express $\beta$-galactosidase (arrows indicate the VUMs in three segments). In the dorsal-most plane $(C)$, a characteristic cluster of three neurons per hemisegment, which expresses $\beta$-galactosidase, is identified by half-circles. The small arrow indicates $\beta$-galactosidase expression in the nuclei of glia of the peripheral nerve. $(D-F)$ Ventral to dorsal focal planes through the ventral nerve cord of an otd mutant embryo at $13 \mathrm{hr}$. The VUMs are missing from their normal position in the mutant (stars). One or two cells per segment are sometimes seen along the ventral midline, but it is unclear whether they are surviving VUMs or are some unidentified cell type normally located at the midline and obscured by the VUMs. The lateral clusters of cells in the ventral and intermediate focal planes appear normal, as do the three-cell clusters in the dorsal focal plane $[(F)$ half-circles]. Side views of wild-type embryos are shown at $11.5(G)$ and $13(H)$ hr. The arrows point to the VUMs, which are initially located in a more dorsal position and finally occupy the ventral midline. (I) Side view of an otd mutant embryo at $11.5 \mathrm{hr}$. At this stage, the VUMs are present in their more dorsal position (arrows). The embryo was identified as mutant on the basis of the abnormal head morphology resulting from the failure of head involution. 


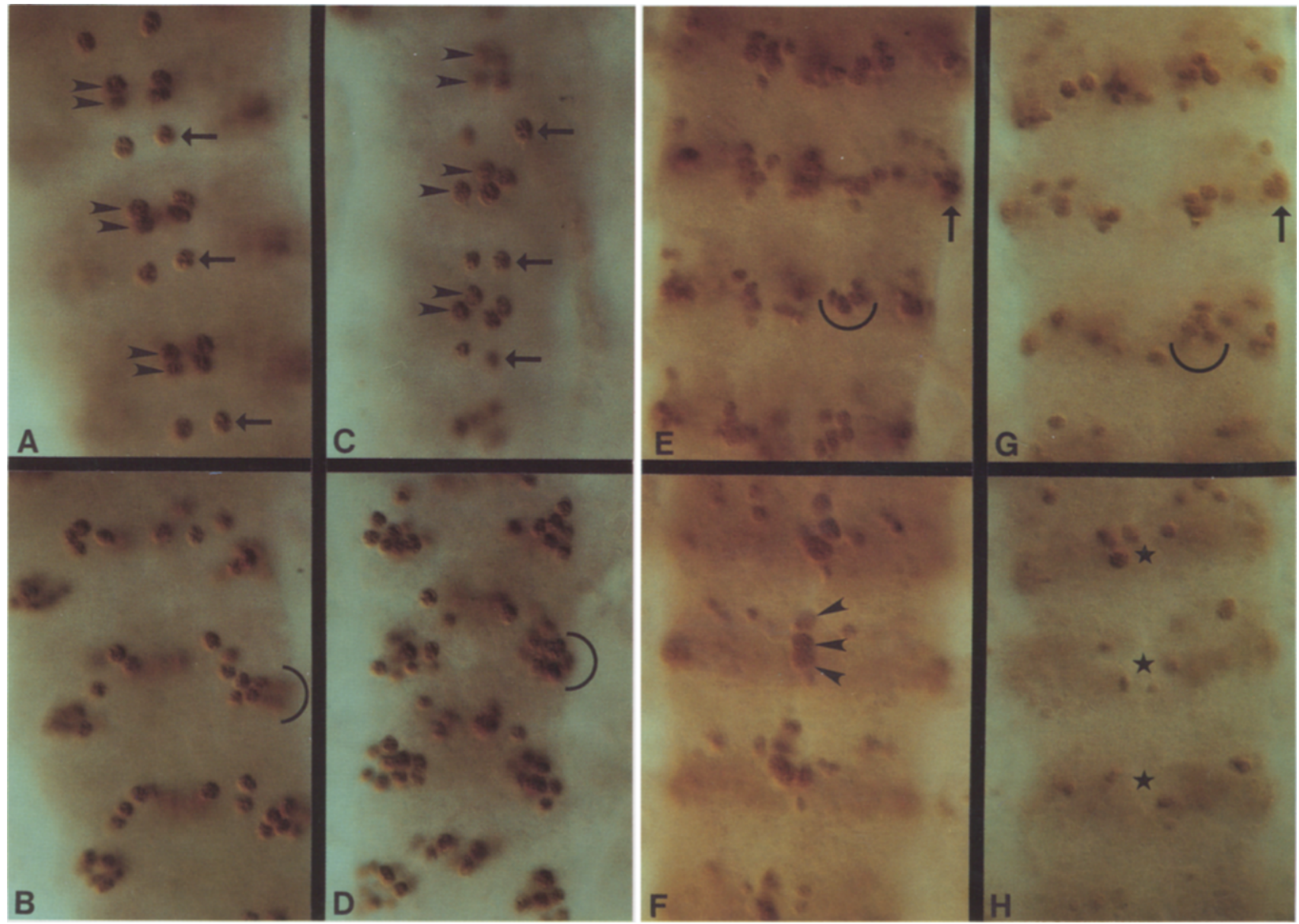

Figure 3. Phenotype of identified neurons in otd mutant embryos. Ventral nerve cords of embryos stained with anti-eve $(A-D)$ or anti-en $(E-H)$ are shown; anterior is up. $(A, B)$ Wild-type embryo stained with anti-eve. The dorsal plane of focus $(A \mid$ shows the identified neurons known as the RP2 neuron (arrow) and the sibling aCC and pCC neurons (arrowheads). The ventral plane $(B)$ shows the ventral-lateral neurons (half-circle) and more medial neurons, which express eve. $(C, D)$ otd mutant embryo stained with antieve. In the dorsal plane $(C)$, the RP2, aCC, and pCC neurons are clearly present; Their positions are slightly perturbed relative to the wild-type embryo, perhaps as a consequence of defects in the axon ladder or as a result of the loss of other cells. In the ventral plane $(D)$, the ventral-lateral and medial neurons are also present and apparently unaffected by the mutation. $(E, F)$ Wild-type embryo stained with anti-en. The dorsal focal plane $(E)$ shows a prominent cluster of five neurons per hemisegment that express en, whereas the ventral view $(F)$ shows a cluster of three to four medial en ${ }^{+}$neurons. $(G, H)$ otd mutant embryo stained with anti-en. $G$ demonstrates that the neurons in the dorsal plane of focus are present and continue to express en, whereas the ventral plane $(H)$ shows that the medial, en ${ }^{+}$neurons are either no longer present in their normal positions or fail to express en.

\section{otd expression during embryogenesis}

To understand the role of the otd gene during embryonic development, we determined the pattern of expression of otd transcripts. In situ hybridization to wild-type embryos at various stages of development demonstrates that otd expression appears at least as early as $2.5 \mathrm{hr}$, at approximately the time when the cellular blastoderm forms. Expression is confined to a broad, circumferential stripe at the anterior end of the embryo, extending from $-70-90 \%$ of egg length (Fig. 7A). The yolk nuclei from this region, which lie in the interior of the embryo, are also labeled (data not shown). Fate map analysis has shown that this portion of the blastoderm gives rise to many of the structures of the larval head (Jürgens et al. 1986). In otd embryos, a number of structures derived from this region of the fate map are absent or defective, as will be described elsewhere (Finkelstein and Perrimon 1990). Following gastrulation, expression of otd persists in the procephalic head region. At $\sim 5-6 \mathrm{hr}$, a second domain of otd expression appears in a longitudinal strip of cells along the ventral midline of the embryo (Fig. 7B and $\mathrm{Cl}$. These cells correspond to the mesectoderm or midline neuroepithelium and will generate a mixed population of neurons and glia (Rothberg et al. 1988; Jacobs and Goodman 1989a,b). Expression of otd continues in the head region and in the ventral nerve cord (Fig. 7D) in embryos as old as $13 \mathrm{hr}$.

\section{Discussion}

The development of the Drosophila embryonic nervous system is a complex process dependent on a precise 
Figure 4. Adult $o c$ phenotype. $(A)$ Scanning electron micrograph of the ocellar region of a wild-type fly. The ocelli (oc) are indicated, as are the postvertical (pvb) and ocellar (ob) bristles. $(B)$ Micrograph of the ocellar region of an adult fly transheterozygous for otd and $o c$ alleles. The ocelli are completely absent and the postvertical and ocellar bristles are missing or abnormal.
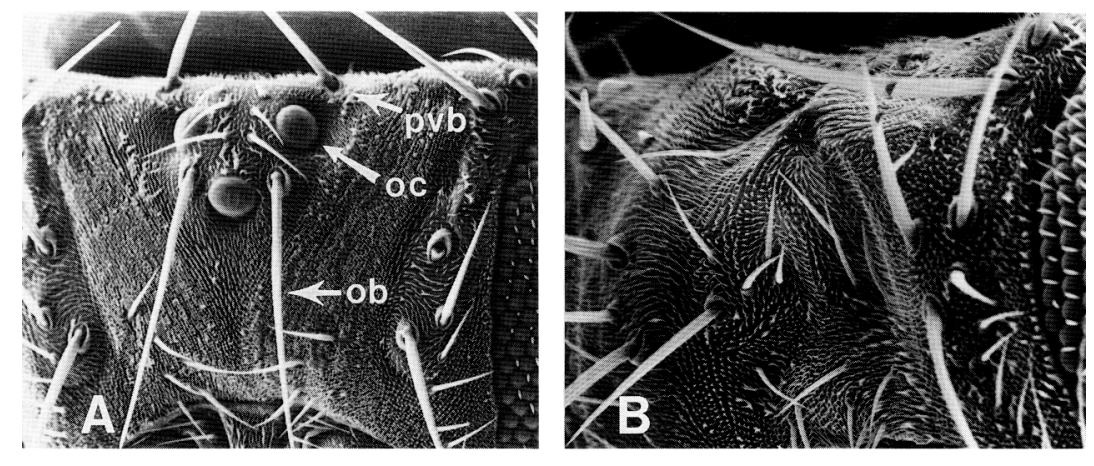

series of events. These events include both the specification of individual cell fates and cell-cell interactions. Embryonic lethal mutations at the otd locus have a specific effect on CNS development and result in the disappearance of identified medial neurons. Perhaps as a consequence of this aberrant development of medial cells, there is also a defect in commissure formation. A similar axonal phenotype has been observed in embryos mutant for Star, spitz, rhomboid, and pointed (Mayer and Nüsslein-Volhard 1988; Bier et al. 1990; D. Smouse, unpubl.),

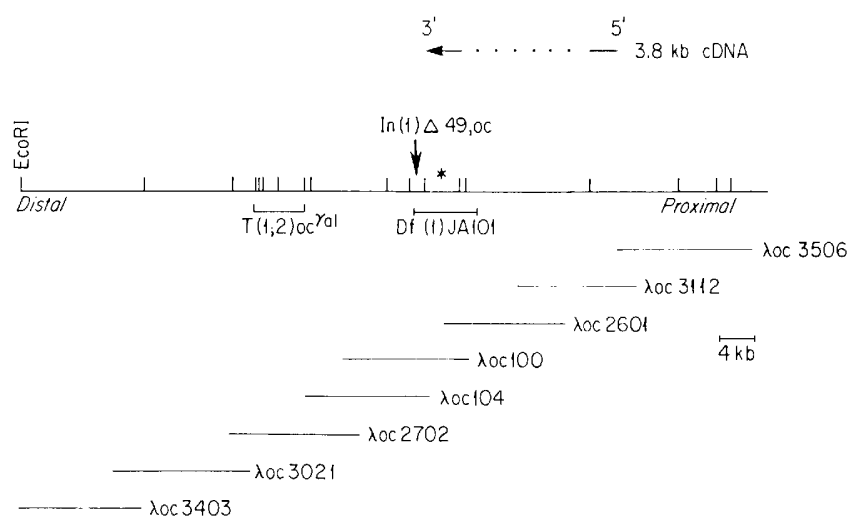

Figure 5. Molecular map of the otd/oc region. The bacteriophage clones shown represent an extension of the walk published previously (Spradling and Mahowald 1981). The EcoRI sites present are indicated, as well as the positions of the molecular alterations detected in the $\operatorname{In}(1) \Delta 49$ oc, $T(1 ; 2)$ oc ${ }^{\text {va1 }}$, and otd ${ }^{\mid A 101}$ mutations. These alterations were mapped by Southern analysis with ${ }^{32} \mathrm{P}$-labeled probes made from various bacteriophage and restriction fragments derived from these phage. The probes were applied to blots containing genomic DNAs digested with different restriction enzymes. The position of the $T(1 ; 2) o c^{y a 1}$ breakpoint is indicated with a bracket because it has been localized as lying between the proximal end of $\lambda$ oc 3021 and the distal end of $\lambda$ oc104. The $o c^{d b}$ chromosome also shows molecular alterations in this region, but because the chromosome from which it is derived is not known, these alterations cannot be confirmed as specific to the mutation. The arrow above the genomic map indicates the position of the 3.8$\mathrm{kb}$ cDNA. The solid portions of the arrow designate the two regions of the bacteriophage walk detected by Southern analysis with the labeled cDNA probe. An asterisk $\left({ }^{*}\right)$ indicates the 4.0 -kb fragment used as a probe in Northern analysis and cDNA library screening. suggesting that these genes may participate in a common developmental pathway. A somewhat similar phenotype is observed in embryos mutant for slit (Rothberg et al. 1988) and single-minded (Thomas et al. 1988); however, these mutations cause a more severe fusion of the CNS. Furthermore, these mutations appear to affect the mesectodermal precursors, themselves, and thus act at an earlier stage of neuronal development than otd. In otd mutant embryos, the precursors for the medial neurons are unaffected, but their progeny do not develop normally. The otd gene product may therefore be required at a later stage for specifying the identities of these precursors or their progeny. In the absence of otd function, the incorrect specification of these neurons results in their death or abnormal development by $13 \mathrm{hr}$.

To gain insight into the mechanism of this mutation, we have analyzed the otd locus at the molecular level. We have identified a transcript from this region that we believe encodes the otd gene product for several reasons. First, it is the only detectable embryonic transcript in the region affected by the orthodenticle deletion otd ${ }^{I A 101}$ and the $o c$ mutations $\operatorname{In}(1) \Delta 49, o c$ and $T(1 ; 2) o c^{\gamma a 1}$. As

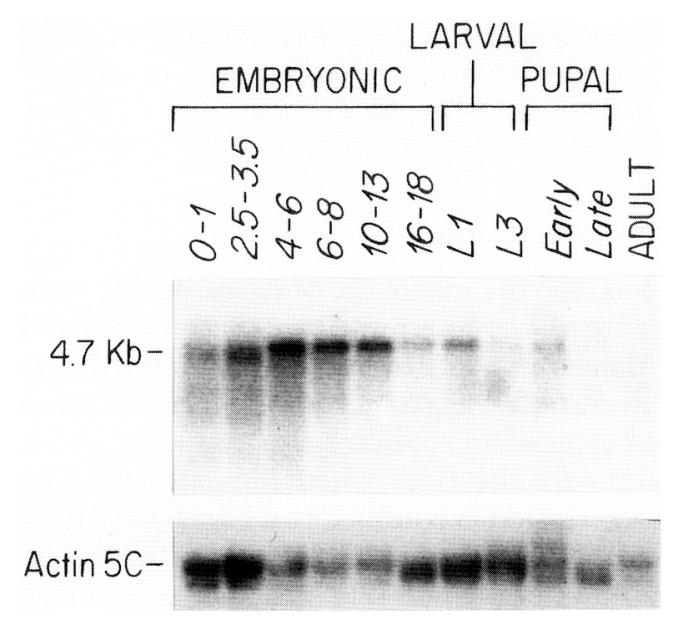

Figure 6. Transcription of the otd gene. Each lane contains 5 $\mu \mathrm{g}$ of poly $(\mathrm{A})+$ RNA derived from the indicated developmental stage. The probe used at the top is the $4.0-\mathrm{kb}$ fragment from bacteriophage $\lambda$ oc100 (see Fig. 5). (Bottom) The same Northern blot that has been stripped and rehybridized with an actin $5 \mathrm{C}$ probe (Fyrberg et al. 1983). 


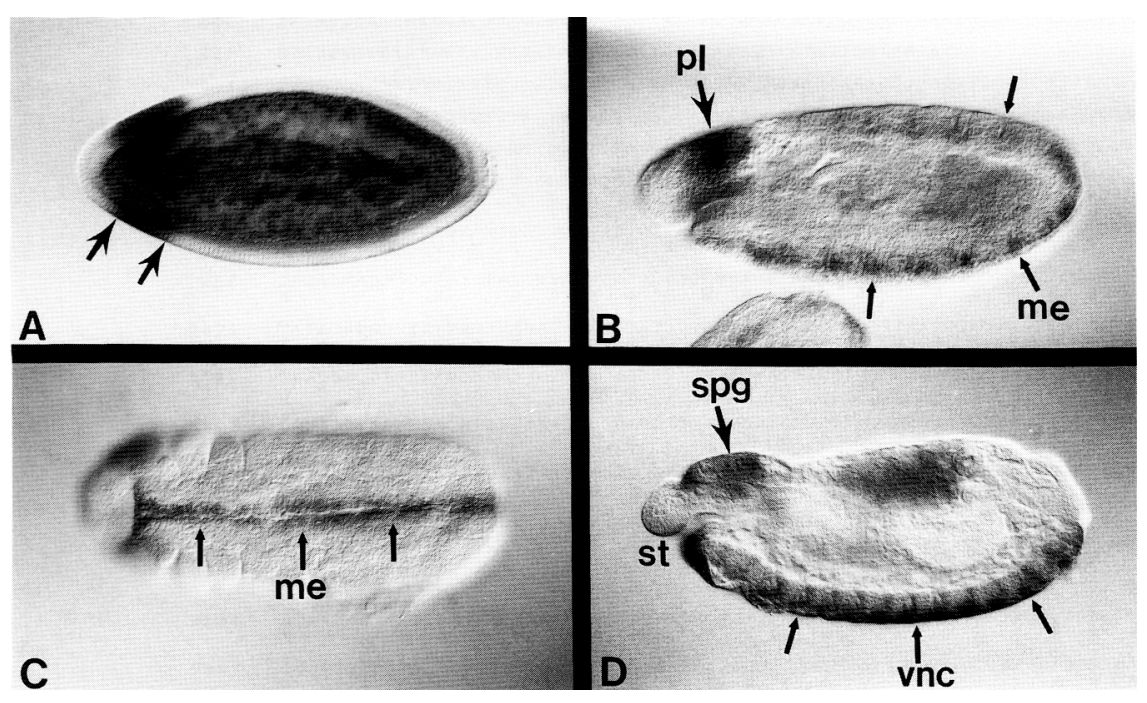

Figure 7. Expression of otd transcripts during embryogenesis. A digoxigenin-labeled DNA probe made from the $4.0-\mathrm{kb}$ EcoRI fragment described in Fig. 5 was hybridized to whole-mount preparations of wild-type embryos. $(A-D)$ Anterior is to the left: $(A)$ Dorsal view; $(C)$ ventral view. $(B$ and $D)$ Dorsal is at the top. Staging of embryos is according to Campos-Ortega and Hartenstein (1985). (A) A cellular blastoderm-stage embryo in which otd expression is confined to a circumferential stripe extending from $70 \%$ to $90 \%$ of egg length (arrows). $(B, C)$ Germ-band-extended embryos showing otd transcription in the mesectoderm (me, small arrows) and procephalic head region $(\mathrm{pl}$, large arrow). (D) A germ-band-retracted embryo showing otd expression in the ventral nerve cord (vnc, small arrows) and in a localized region of the head that includes the supraesophageal ganglion (spg, large arrow). can be seen in Figure 5 , the oc viable breakpoints lie distal to the region corresponding to the 3.8 -kb cDNA,

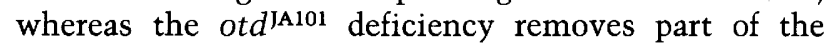
DNA encoding the transcript. Second, the period of highest expression of the transcript (between $\sim 4$ and 13 $\mathrm{hr}$ of embryogenesis) coincides with the time of construction of the nervous system. Finally, in situ hybridization to embryos shows mRNA expression at the ventral midline and in the head region, the two foci most affected by otd mutations.

It is interesting to note that as mentioned above, the molecular alterations associated with the oc phenotype lie $3^{\prime}$ to the region of the bacteriophage walk corresponding to the $3.8-\mathrm{kb}$ cDNA. These molecular alterations could produce the $o c$ phenotype by disrupting a control region required for regulation of the otd mRNA during the period of ocelli development. Alternatively, these alterations could affect a more distal exon not detected in our analysis but necessary for ocelli formation.

The most striking feature of the otd gene is the presence of a homeo domain in its predicted protein product. This suggests a DNA-binding and possible transcriptional regulatory function for the protein. In such a model, the otd gene product might contribute to the specification or maintenance of particular cell fates in the developing embryonic CNS by activating or repressing particular target genes in these cells. The development of identified medial neurons, including the VUMs and the progeny of the MNB, is affected, either directly or indirectly, by the absence of otd gene product. The genes mentioned above, which have been implicated in the development of the medial neurons, may be potential targets for the otd protein. To further understand its role in nervous system development, it will be important to obtain antibodies to the otd protein to identify the specific cells in which it is expressed. Further studies should also provide insight into the function of otd during the development of the ocelli.
It should be noted that several other homeo box-containing Drosophila genes are expressed in specific subsets of neuronal cells. The obvious importance of these genes in early processes of pattern formation suggests that homeo box genes may also be involved in determining the fates of neurons. For instance, the pattern of expression in the CNS of the homeo box gene en is similar in two distantly related insect species, grasshoppers and flies (Patel et al. 1989b). The evolutionary conservation of this pattern suggests an important role for $e n$ in neurogenesis. However, the actual functions of homeo box genes in the embryonic nervous system have been analyzed in only a few cases. The pair-rule genes fushi tarazu and eve are required for the correct establishment of cell fate in at least some of the identified neurons that express them (Doe et al. 1987, 1988). The homeo box gene cut (Blochlinger et al. 1988) is necessary to establish the identity of the external sensory organs in Drosophila embryos; in the absence of cut expression, these organs are transformed into chordotonal sense organs (Bodmer et al. 1987). otd is a new member of the class of homeo box-containing genes required for the development of subsets of embryonic neurons.

Finally, two unexpected results from the present study are important to note. First, the circumferential stripe of mRNA expression present during the blastoderm stage suggests that otd is regulated by maternal positional information. The early appearance of this domain may be the result of direct transcriptional activation of otd by the maternally deposited gradient of bicoid protein (Driever and Nüsslein-Volhard 1988). Driever et al. (1989) have postulated the existence of a gene or group of genes (referred to as gene $\mathrm{X}$ ) directly regulated by bicoid and required for the development of a large anterior region of the larval head. The early otd expression pattern and the head defects present in mutant embryos make otd an excellent candidate for such a gene (Finkelstein and Perrimon 1990). The second striking result is the 
Finkelstein et al.

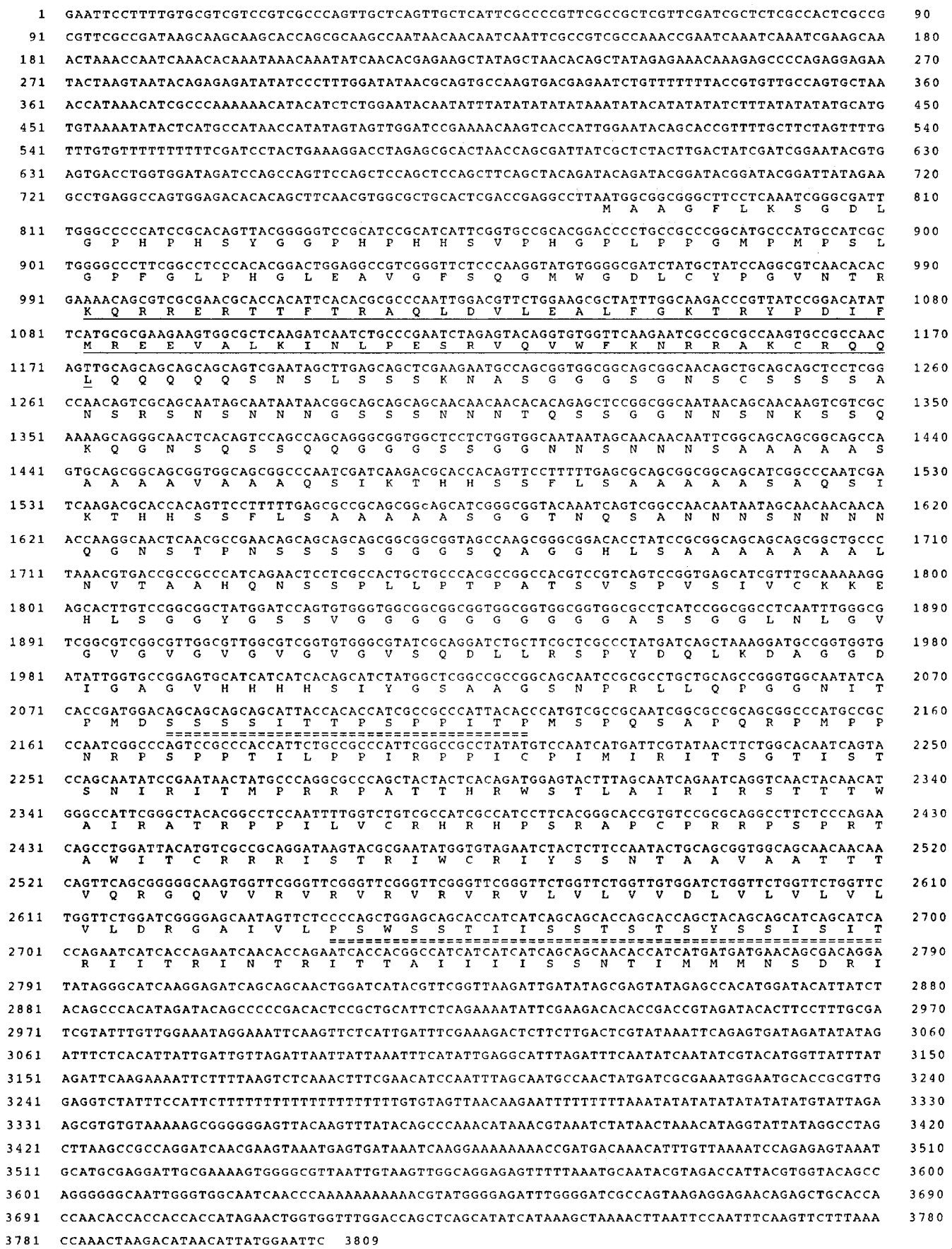

Figure 8. The nucleotide sequence of the $3.8-\mathrm{kb}$ cDNA clone and the amino acid sequence of the putative otd gene product. The nucleotide and inferred amino acid sequences (see text) of the otd cDNA are indicated. The cDNA clone was generated as an EcoRI fragment in the construction of the cDNA library (see Materials and methods). The homeo domain sequence is underlined, and two candidate PEST sequences are indicated by double lines.

possible functional similarity between the otd and $b i$ coid homeo domains. If the DNA binding specificities of these two proteins are similar, the otd gene product may compete with the bicoid protein in the activation or repression of potential downstream genes. It will therefore be important to identify the genes that interact with otd during embryonic pattern formation.

\section{Materials and methods}

Strains

There are six ethylmethane-sulfonate (EMS)-induced mutations at the otd locus: otd ${ }^{E H 630}$, otd ${ }^{E H 768}$ (Eberl and Hilliker 1988); otd ${ }^{X C 86}$, otd ${ }^{Y H 13}$, otd ${ }^{X D 87}$ (Wieschaus et al. 1984); ot $d^{\text {NP162 }}$ (N. Perrimon and E. Noll, unpubl.); and one X-ray-induced allele 


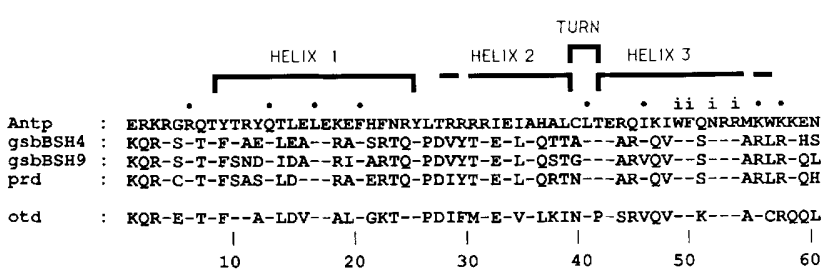

Figure 9. Analysis of the otd homeo domain sequence. The homeo domain comparison shown is adapted from Scott et al. (1989). The amino acid sequence of the Antennapedia domain is shown as a reference with dashes in subsequent sequences indicating identical residues in the other homeo domains. The predicted positions of helices 1,2 , and 3 are shown as well as invariant (i) and highly conserved (dots) amino acids.

otdiA101 (G. Lefevre, pers. comm.). Because the EMS alleles behave identically to ot $d^{I A 101}$, which is a null allele at the molecular level, they are believed to be null mutations. Three $o c$ alleles, In(1) 449 , oc (Bedichek 1934), T(1;2)oc ${ }^{\text {ral }}$ (Wakimoto and Spradling 1981), and $o c^{d b}$ (Mohler 1984) were examined. The chromosomes carrying otd and $o c$ mutations are maintained as $F M 7 c, C l B$, Binsn, or Binsc stocks; descriptions of the balancer chromosomes can be found in Lindsley and Grell (1968). All experiments were performed at $25^{\circ} \mathrm{C}$ on standard Drosophila medium.

The lacZ strain used in the phenotypic analysis of otd was generated by using the "enhancer trap" technique (O'Kane and Gehring 1987) in our laboratory: The strain contains an insert of the $\beta$-galactosidase gene at $45 \mathrm{C}$.

\section{Immunohistochemistry}

Immunohistochemistry was performed as described in Smouse et al. (1988). Embryos were dechorionated in 50\% Chlorox bleach, fixed in a $1: 1 \mathrm{mix}$ of $4 \%$ paraformaldehyde/heptane, devitellinized in methanol/heptane, washed in PBS plus $0.1 \%$ Triton X-100 (PT), and stained with antibodies in PT plus $2 \%$ bovine serum albumin. The antibodies used were fluoresceinconjugated goat anti-HRP (Cappel), rabbit anti-eve (M. Frasch and M. Levine), mouse anti-en [mAb 4D9 (Patel et al. 1989b)], and mouse anti- $\beta$-galactosidase (Promega-Biotec).

\section{Scanning electron microscopy}

Adult flies were prepared for scanning electron microscopy (SEM) according to Shepard et al. (1989). Flies were preserved in $70 \%$ ethanol, dehydrated through several washes of $95 \%$ and absolute ethanol, critical-point-dried, sputter-coated, and viewed with an AMR scanning electron microscope (model 1000).

\section{In situ hybridization analysis}

In situ hybridization to whole-mount embryos using digoxigenin-labeled probes was performed according to Tautz and Pfeifle (1989), except that embryos were dehydrated, treated with acetone, and mounted in Euparal (Asco Labs.). Embryos were observed with a Zeiss Axiophot microscope.

\section{Northern blots}

Five micrograms of poly $(A)^{+}$RNA derived from each of the indicated stages of Drosophila development was electrophoresed on formaldehyde/agarose gels and blotted onto nitrocellulose membranes (Schleicher \& Schuell). Blots were prehybridized $150 \%$ formamide, $5 \times$ SSCPE, $5 \times$ Denhardt's solution, 500 $\mu \mathrm{g} / \mathrm{ml}$ herring sperm DNA, $0.1 \%$ SDS) for at least $6 \mathrm{hr}$ and hybridized $150 \%$ formamide, $5 \times$ SSCPE, $10 \%$ dextran sulfate, $1 \times$ Denhardt's solution, $100 \mu \mathrm{g} / \mathrm{ml}$ herring sperm DNA, $0.1 \%$ SDS) overnight. Blots were washed in $2 \times \mathrm{SSC} / 0.1 \%$ SDS twice at room temperature ( 5 min per wash) and three times at $68^{\circ} \mathrm{C}$ (1 hr per wash) and exposed to Kodak X-Omat film. For rehybridization, probe was stripped by washing for $30 \mathrm{~min}$ at $68^{\circ} \mathrm{C}$ in $1 \times$ wash buffer [15× wash buffer is $50 \mathrm{mM}$ Tris $(\mathrm{pH} 7.4), 20 \mathrm{~mm}$ EDTA, $0.5 \%$ SDS, $1 \times$ Denhardt's solution] and for an additional $30 \mathrm{~min}$ at $68^{\circ} \mathrm{C}$ in $1 \times$ wash buffer, including $50 \%$ formamide. Southern blot analysis was performed under identical conditions, except that electrophoresis was performed in agarose gels without formaldehyde. All hybridization probes were made by the random primer method (Feinberg and Vogelstein 1983) by using [ $\left.{ }^{32} \mathrm{P}\right] \mathrm{dCTP}$ (NEN) to a sp. act. of $1 \times 10^{9}$ to $2 \times 10^{9} \mathrm{cpm} / \mu \mathrm{g}$ and were used at an approximate concentration of $10^{6} \mathrm{cpm} / \mathrm{ml}$ in hybridizations.

\section{Isolation of $\mathrm{cDNA}$ clones}

otd cDNA clones were isolated from a 9- to $12-\mathrm{hr}$ size-selected embryonic library constructed by $\mathrm{K}$. Zinn. The library was plated at a density of $\sim 30,000$ plaques per $150-\mathrm{mm}$ plate and transferred to nitrocellulose filters. The filters were washed for $1 \mathrm{hr}$ at $68^{\circ} \mathrm{C}(1 \times \mathrm{SSC}, 0.5 \%$ SDS $)$, prehybridized $(50 \%$ formamide, $1 \mathrm{M} \mathrm{NaCl}, 0.625 \times$ Denhardt's solution, $50 \mathrm{~mm}$ Tris (pH 7.5), $250 \mu \mathrm{g} / \mathrm{ml}$ herring sperm DNA, $0.5 \%$ SDS) for $2 \mathrm{hr}$ at $42^{\circ} \mathrm{C}$ and hybridized overnight in the same buffer, including ${ }^{32} \mathrm{P}$-labeled probe at a final concentration of $10^{6} \mathrm{cpm} / \mathrm{ml}$. Filters were washed once briefly at room temperature $(2 \times \mathrm{SSC}, 0.5 \%$ SDS $)$ and twice at $55^{\circ} \mathrm{C}(2 \times \mathrm{SSC}, 0.5 \%$ SDS, and then $0.1 \times$ SSC, $0.5 \%$ SDS, 1 hr per wash) and exposed to Kodak X-Omat film. The probe used for screening was the $4.0-\mathrm{kb}$ EcoRI genomic DNA fragment derived from bacteriophage $\lambda$ oc 100 (see Fig. 5).

\section{DNA sequencing and sequence analysis}

For sequence analysis, the $3.8-\mathrm{kb}$ cDNA clone was subcloned into the pBSK vector (Stratagene) at the EcoRI site. Nested exonuclease III deletions spanning the cDNA were generated by using the Erase-a-Base system (Promega) and sequenced by the dideoxy chain-termination method of Sanger et al. (1977). Sequencing was performed on both strands through the coding region, by using multiple overlapping clones throughout, until unambiguous data were obtained. The resulting nucleotide sequence was translated and compared to the Genbank and NBRF data bases with the FASTP program (Lipman and Pearson 1985).

\section{Acknowledgments}

We are indebted to E. Wieschaus, D. Eberl, G. Lefevre, D. Mohler, and the Bowling Green Stock Center for Drosophila stocks, and to $\mathrm{K}$. Zinn and $\mathrm{C}$. Goodman for providing the embryonic cDNA library. We thank J. Levine for technical assistance in chromosome walking, $M$. Frasch and $M$. Levine for the anti-eve antibody, and N. Patel and C. Goodman for the anti-en antibody. We also thank E. Wieschaus and N. Patel for helpful discussions about the otd phenotype, as well as R. Doolittle and C. Desplan for assistance with the sequence analysis. R.F. was supported by a National Institutes of Health (NIH) postdoctoral fellowship. D.S. was supported, in part, by NIH grant HD23684. This work was supported by Howard Hughes Medical Institute, 
a grant from the American Cancer Society to N.P., and NIH grant GM27875 to A.C.S.

The publication costs of this article were defrayed in part by payment of page charges. This article must therefore be hereby marked "advertisement" in accordance with 18 USC section 1734 solely to indicate this fact.

\section{Note added in proof}

Sequence data described in this paper have been submitted to EMBL/GenBank Data Libraries.

\section{References}

Bedichek, S. 1934. New mutants. Dros. Inf. Serv. 2: 9.

Bier, E., L.Y. Jan, and Y.N. Jan. 1990. rhomboid, a gene required for dorsoventral axis establishment and peripheral nervous system development in Drosophila melanogaster. Genes Dev. 4: 190-203.

Blochlinger, K., R. Bodmer, J. Jack, L.Y. Jan, and Y.N. Jan. 1988. Primary structure and expression of a product from cut, a locus involved in specifying sensory organ identity in Drosophila. Nature 333: 629-635.

Bodmer, R., S. Barbel, S. Sheperd, J.W. Jack, L.Y. Jan, and Y.N. Jan. 1987. Transformation of sensory organs by mutations of the cut locus of D. melanogaster. Cell 51: 293-307.

Campos-Ortega, J.A. 1988. Cellular interactions during early neurogenesis of Drosophila melanogaster. Trends Neurosci. 11: $400-405$.

Campos-Ortega, J.A. and V. Hartenstein. 1985. Histogenesis and organogenesis. In The embryonic development of Drosophila melanogaster pp. 85-165. Springer-Verlag, New York.

Cavener, D.R. 1987. Comparison of the consensus sequence flanking translational start sites in Drosophila and vertebrates. Nucleic Acids Res. 15: 1353-1361.

Crews, S.T., J.B. Thomas, and C.S. Goodman. 1988. The Drosophila single-minded gene encodes a nuclear protein with sequence similarity to the per gene product. Cell 52: 143-151.

Doe, C.Q. and C.S. Goodman. 1985a. Early events in insect neurogenesis. I. Development and segmental differences in the pattern of neuronal precursor cells. Dev. Biol. 111: 193205.

- 1985b. Early events in insect neurogenesis. II. The role of cell interactions and cell lineage in the determination of neuronal precursor cells. Dev. Biol. 111: 206-219.

Doe, C.Q., D. Smouse, and C.S. Goodman. 1988. Control of neuronal fate by the Drosophila segmentation gene evenskipped. Nature 333: 376-378.

Doe, C.Q., Y. Hiromi, W.J. Gehring, and C.S. Goodman. 1987. Expression and function of the segmentation gene fushi tarazu during Drosophila neurogenesis. Science 239: 170175 .

Dover, G.A. 1989. Slips, strings and species. Trends Genet. 5: $100-102$

Driever, W. and C. Nüsslein-Volhard. 1988. A gradient of $b i$ coid protein in Drosophila embryos. Cell 54: 83-93.

Driever, W., G. Thoma, and C. Nüsslein-Volhard. 1989. Determination of spatial domains of zygotic gene expression in the Drosophila embryo by the affinity of binding sites for the bicoid morphogen. Nature 340: 363-367.

Eberl, D.F. and A.J. Hilliker. 1988. Characterization of X-linked recessive lethal mutations affecting embryonic morphogenesis in Drosophila melanogaster. Genetics 118: 109-120.

Feinberg, A.P. and B. Vogelstein. 1983. A technique for radiolabeling DNA restriction endonuclease fragments to high spe- cific activity. Anal. Biochem. 132: 6-13.

Finkelstein, R. and N. Perrimon. 1990. The orthodenticle gene is regulated by bicoid and torso and specifies Drosophila head development. Nature 346: 485-488.

Fyrberg, E.A., J.W. Mahaffey, B.J. Bond, and N. Davidson. 1983. Transcripts of the six Drosophila actin genes accumulate in a stage- and tissue-specific manner. Cell 53: 115-123.

Goodman, C.S., M.J. Bastiani, C.Q. Doe, S. du Lac, S.L. Helfand, J.Y. Kuwada, and J.B. Thomas. 1984. Cell recognition during neuronal development. Science 225: 1271-1279.

Hanes, S.D. and R. Brent. 1989. DNA specificity of the bicoid activator protein is determined by homeodomain recognition helix residue 9. Cell 57: 1275-1283.

Hartenstein, V. and J.A. Campos-Ortega. 1984. Early neurogenesis in wild type Drosophila melanogaster. Wilhelm Roux's Arch. Dev. Biol. 193: 308-325.

Jacobs, R. and C.S. Goodman. 1989a. Embryonic development of axon pathways in the Drosophila CNS. I. A glial scaffold appears before the first growth cones. J. Neurosci. 9: 24022411.

- 1989b. Embryonic development of axon pathways in the Drosophila CNS. II. Behavior of pioneer growth cones. J. Neurosci. 9: 2412-2422.

Jan, L.Y. and Y.N. Jan. 1982. Antibodies to horseradish peroxidase as specific neuronal markers in Drosophila and grasshopper embryos. Proc. Nat1. Acad. Sci. 79: 2700-2704.

Jürgens, G., R. Lehmann, M. Schardin, and C. Nüsslein-Volhard. 1986. Segmental organization of the head in the embryo of Drosophila melanogaster. Wilhelm Roux's Arch. Dev. Biol. 195: 359-377.

Kozak, M. 1984. Compilation and analysis of sequences upstream from the translational start site in eukaryotic mRNA. Nucleic Acids Res. 12: 857-872.

Kuwada, J.Y. and C.S. Goodman. 1985. Neuronal determination during embryonic development of the grasshopper nervous system. Dev. Biol. 110: 114-126.

Lehmann, R., U. Dietrich, F. Jimenez, and J.A. Campos-Ortega. 1981. Mutations of early neurogenesis in Drosophila. Wilhelm Roux's Arch. Dev. Biol. 190: 226-229.

Lehmann, R., F. Jimenez, U. Dietrich, and J.A. Campos-Ortega. 1983. On the phenotype and development of mutants of early neurogenesis in Drosophila melanogaster. Wilhelm Roux's Arch. Dev. Biol. 192: 62-72.

Lindsley, D.L. and E.H. Grell. 1968. Genetic variations of Drosophila melanogaster. Carnegie Inst. Wash. Publ. 627.

Lipman, D. and W. Pearson. 1985. Rapid and sensitive protein similaritysearches. Science 227: 1435-1441.

Mayer, U. and C. Nüsslein-Volhard. 1988. A group of genes required for pattern formation in the ventral ectoderm of the Drosophila embryo. Genes Dev. 2: 1496-1511.

McGinnis, W., M.S. Levine, E. Hafen, A. Kuroiwa, and W.J. Gehring. 1984. A conserved DNA sequence in homeotic genes of the Drosophila Antennapedia and bithorax complexes. Nature 308: 428-433.

Mohler, D. 1984. New mutants. Dros. Inf. Serv. 60: 236.

O'Kane, C.J. and W.J. Gehring. 1987. Detection in situ of genomic regulatory elements in Drosophila. Proc. Natl. Acad. Sci. 84: 9123-9127.

Patel, N. H., B. Schafer, C.S. Goodman, and R. Holmgren. 1989a. The role of segment polarity genes during Drosophila neurogenesis. Genes Dev. 3: 890-904.

Patel, N.H., E. Martin-Blanco, K.G. Coleman, S.J. Poole, M.C. Ellis, T.B. Kornberg, and C.S. Goodman. 1989b. Expression of engrailed proteins in arthropods, annelids, and chordates. Cell 58: 955-968.

Poole, S.J., L.M. Kauvar, B. Drees, and T. Kornberg. 1985. The 
engrailed locus of Drosophila: Structural analysis of an embryonic transcript. Cell 40: 37-43.

Proudfoot, N.J. and G.G. Brownlee. 1976. 3' Non-coding region sequences in eukaryotic mRNA. Nature 263: 211-214.

Rogers, S., R. Wells, and M. Rechsteiner. 1986. Amino acid sequences common to rapidly degraded proteins: The PEST hypothesis. Science 234: 364-368.

Rothberg, J.M., D.A. Hartley, Z. Walther, and S. Artavanis-Tsakonas. 1988. slit: An EGF-homologous locus of D. melanogaster involved in the development of the embryonic central nervous system. Cell 55: 1047-1059.

Sanger, F., S. Nicklen, and A.R. Coulson. 1977. DNA sequencing with chain-terminating inhibitors. Proc. Natl. Acad. Sci. 74: 5463-5467.

Scott, M.P., J.W. Tamkun, and G.W. Hartzell. 1989. The structure and function of the homeodomain. Biochim. Biophys. Acta 989: 25-48.

Shepard, S.B., S.A. Broverman, and M.A. Muskavitch. 1989. A tripartite interaction among alleles of Notch, Delta, and Enhancer of split during imaginal development of Drosophila melanogaster. Genetics 122: 429-438.

Smouse, D., C.S. Goodman, A.P. Mahowald, and N. Perrimon. 1988. polyhomeotic: A gene required for the embryonic development of axon pathways in the central nervous system of Drosophila. Genes Dev. 2: 830-842.

Spradling, A.C. and A.P. Mahowald. 1981. A chomosome inversion alters the pattern of specific DNA replication in Drosophila follicle cells. Cell 27: 203-209.

Tautz, D. and C. Pfeifle. 1989. A nonradioactive in situ hybridization method for the localization of specific RNAs in Drosophila embryos reveals a translational control of the segmentation gene hunchback. Chromosoma 98: 81-85.

Thomas, J.B., S.T. Crews, and C.S. Goodman. 1988. Molecular genetics of the single-minded locus: A gene involved in the development of the Drosophila nervous system. Cell 52: $133-141$.

Treisman, J., P. Gonczy, M. Vashishtha, E. Harris, and C. Desplan. 1989. A single amino acid can determine the DNA binding specificity of homeodomain proteins. Cell 59: 553562.

Wakimoto, B. and A.C. Spradling. 1981. Isolation of mutations in the $\mathrm{X}$ chromosome chorion gene region. Carnegie Inst. Wash. Year Book 81: 190-191.

Wharton, K.A., K.M. Johansen, T. Xu, and S. Artavanis-Tsakonas. 1985a. Nucleotide sequence from the neurogenic locus Notch implies a gene product that shares homology with proteins containing EGF-like repeats. Cell 43: 567581.

Wharton, K.A., B. Yedvobnick, V.G. Finnerty, and S. ArtavanisTsakonas. 1985b. opa: A novel family of transcribed repeats shared by the Notch locus and other developmentally regulated loci in D. melanogaster. Cell 43: 567-581.

Wieschaus, E., C. Nüsslein-Volhard, and G. Jürgens. 1984. Mutations affecting the pattern of the larval cuticle in Drosophila melanogaster. 3. Zygotic loci on the $X$-chromosome and 4th chromosome. Wilhelm Roux's Arch. Dev. Biol. 193: $296-307$. 


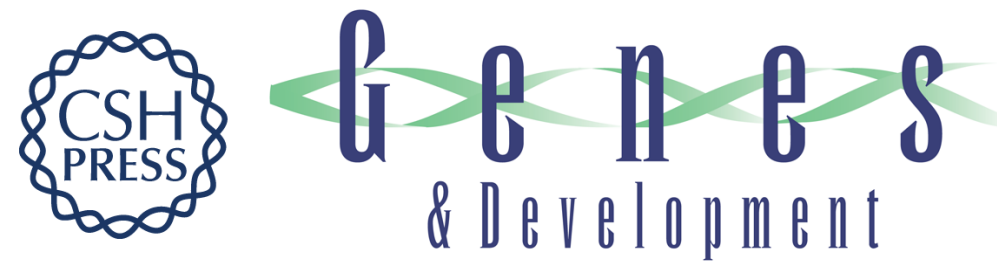

\section{The orthodenticle gene encodes a novel homeo domain protein involved in the development of the Drosophila nervous system and ocellar visual structures.}

R Finkelstein, D Smouse, T M Capaci, et al.

Genes Dev. 1990, 4:

Access the most recent version at doi:10.1101/gad.4.9.1516

References This article cites 52 articles, 14 of which can be accessed free at: http://genesdev.cshlp.org/content/4/9/1516.full.html\#ref-list-1

License

Email Alerting Receive free email alerts when new articles cite this article - sign up in the box at the top Service right corner of the article or click here.

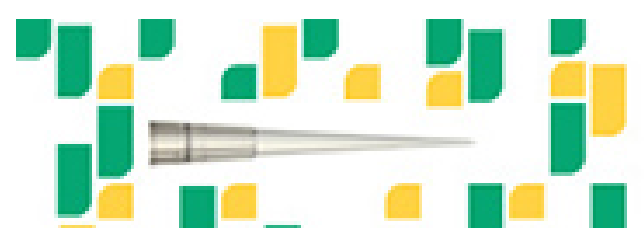

Focused on your science. 